\title{
Immersive teacher training experience on the methodology of problem posing and solving in Mathematics
}

\author{
Alice Barana ${ }^{1}$, Anna Brancaccio ${ }^{2}$, Alberto Conte ${ }^{1}$, Cecilia Fissore ${ }^{1}$, Francesco Floris ${ }^{1}$, \\ Marina Marchisio ${ }^{1}$, Claudio Pardini ${ }^{3}$ \\ ${ }^{1}$ Dipartimento di Matematica, University of Turin, Italy ${ }^{2}$ MIUR, Rome, Italy ${ }^{3}$ ISS Carlo \\ Anti, Villafranca di Verona (VR), Italy.
}

\begin{abstract}
In an Italian and European context, one of the fundamental skills in Mathematics is the ability to solve problems in everyday situations, often linked to everyday life. For this reason, the problem posing and solving methodology plays a fundamental role in the process of teaching and learning Mathematics. This paper presents the results of the immersive experience "Mathematical Exploration with Problem Posing and Solving", included in the teacher training activities proposed by the national PP\&S Problem Posing \& Solving - Project of the Italian Ministry of Education, which aims at enhancing the teaching and learning of Mathematics by using new methodologies and technologies. In particular, the focus will be on the work and considerations of the 50 teachers who took part in the project, from both primary and secondary school. They were guided through the individual step-by-step creation of a contextualized problem, following a process guided through stimulus-based questions. This immersive experience brought about the production of valid problems and was full of very stimulating teachers' considerations on the various phases of the problem posing and solving.
\end{abstract}

Keywords: Contextual teaching; Contextualized problem; Mathematics Education; Problem posing; Problem solving; Teacher Training. 


\section{Introduction}

The Problem posing and solving methodology plays a fundamental role in the process of teaching and learning Mathematics and in promoting a process of mathematization and modeling of reality (Baroni \& Bonotto, 2015). As explained in many Italian national documents, the teaching of Mathematics should start with the use of language and mathematical reasoning as tools for the interpretation of reality and not only as baggage of notions (Unione Matematica Italiana, 2001). The characteristic of mathematical practice is the solving of problems, which has to be considered as an authentic and meaningful task, often linked to everyday life, and not only as a repetitive exercise or question to answer by simply recalling a definition or a rule (MIUR, 2012). Also at a European level, mathematical competence is described as the ability to develop and apply mathematical thinking and intuition to solve a series of problems in everyday situations (European Parliament and Council, 2018). A change in the teaching of Mathematics has therefore become necessary and in 2012 the Italian Ministry of Education engaged in an action aimed at improving the quality of the educational process by acting on teachers' training through the PP\&S (Problem Posing and Solving) Project (Brancaccio et al., 2015). The project promotes the training of Italian teachers of lower and upper secondary schools on innovative teaching methods, supported by the use of ICT and the creation of a culture of Problem Posing and Solving ( Barana, Fioravera, \& Marchisio, 2017b).

This paper discusses a teaching training experience which took place during a 2 hours immersive workshop, "Mathematical Exploration with Problem Posing and Solving", at the Didacta Italia 2018 Fair. The workshop is included in the teacher training activities proposed by the PP\&S; other activities are: face-to-face training, online training modules, weekly online tutoring, online asyncronus collaboration and collaborative learning within a learning community (Barana et al., 2018a).

\section{State of the art}

\subsection{Problem Solving}

The term "problem-solving" refers to mathematical tasks that have the potential to provide intellectual challenges for enhancing students' mathematical understanding and development (National Council of Teachers of Mathematics, 2000). One of the objectives of Mathematics learning is to solve the problems that include the ability to understand the problem, devise a mathematical model, develop the solving process and interpret the obtained solution (Samo, Darhim, \& Kartasasmita, 2017). Mathematical problems are central in mathematical practice in order to develop the discipline and to foster student learning (Pólya, 1945). Mathematics should not be considered different from the possible daily activities of the students. A real situation in which the student might find himself can 
be used to propose a problem, in order to bring together the teaching and learning practices of school Mathematics and the wealth of experiences that students develop outside of the school (D’Amore \& Pinilla, 2006). According to Samo, Bana and Kartasasmita (2017) "contextual teaching and learning is a learning which links the material with the real-world context of students' everyday life either within family, community, environment, and the world of work so that students are able to make connections between knowledge possessed by its application in everyday life”. In fact, problem solving can stimulate interest and motivation towards the study of Mathematics by creating a bridge between school and extracurricular Mathematics, bringing out realistic considerations and developing modeling skills (i.e. recognizing when and how to use subject knowledge to address and solve problems in hands-on situations in the real world) (Baroni \& Bonotto, 2015). Furthermore, by solving mathematical problems students acquire ways of thinking, habits of persistence and curiosity, and confidence in unfamiliar situations that serve them well outside the Mathematics classroom (National Council of Teachers of Mathematics, 2000). In order to gain experience on problem solving, students should solve various types of problems in their own way on a regular basis and over a prolonged period of time. Non-routine problems and open problems should be used to offer students a wide range of possibilities for choosing and making decisions. Students' resolution of a problem can be used to evaluate progress in the problem solving skill, using a rubric score scale (Leong \& Janjaruporn, 2015). The analysis of the ways in which mathematical problems are formulated and of the process involved in solving problems generates important information to structure learning environments in order to guide students' construction of mathematical concepts (Liljedahl, Santos-Trigo, Malaspina, \& Bruder, 2016).

\subsection{Problem Posing}

Problem posing is an important component of the Mathematics curriculum, and it is considered to be an essential part of mathematical doing (National Council of Teachers of Mathematics, 2000). It involves the creation of new problems and questions aimed at exploring a given situation as well as the reformulation of a problem during the process of solving it (Lavy \& Shriki, 2007). Kilpatrick (1987) marked a historic milestone in research related to problem posing: he pointed out that problem formulating should be viewed not only as a goal of instruction but also as a means of instruction and that the students should be given opportunities to live the experience of discovering and posing their own problems. Kilpatrick also pointed out how all problems that students solve have been posed by another person, but in the real life many problems are created or discovered by the solver, who gives the problem an initial formulation (Liljedahl et al., 2016). According to Lavy \& Shriki (2007), providing students with opportunities to pose their own problems can foster more diverse and flexible thinking, enhance students' problem solving skills, broaden their perception of Mathematics and enrich and consolidate basic concepts. 
Stoyanova and Ellerton (1996) considered mathematical problem posing as "the process by which, on the basis of mathematical experience, students construct personal interpretations of concrete situations and formulate them as meaningful mathematical problems” (p. 519). They identified three categories of problem-posing situations: free, semi-structured, or structured. In free situations, students pose problems without restrictions; semi-structured situations refer to those circumnstances in which students explore a given open situation and they have to complete it; in structured situations students pose problems by reformulating already solved problems or by varying the conditions of given problems (Singer, Ellerton \& Cai, 2015).

In conclusion, problem posing is an opportunity for interpretation and critical analysis of reality since: (a) the students have to discern significant data from immaterial data; (b) they must discover the relations between the data; (c) they must decide whether the information in their possession is sufficient to solve the problem; and (d) they have to investigate if the numerical data involved is numerically and/or contextually coherent.

\subsection{The problem posing and solving in the PP\&S Project}

In the PP\&S Project, we add two further aspects to problem posing and solving:

- $\quad$ use of an ACE (Advanced Computing Environment) for problem formulation, presentation, resolution and generalization (Barana, Fioravera, \& Marchisio, 2017a);

- automatic formative assessment with adaptive questions aimed at teaching students how to solve problems, guiding them step-by-step with interactive feedback in the solving process, through an ACE and an AAS (Automatic Assesment System) (Barana, Conte, Fioravera, Marchisio, \& Rabellino, 2018b; Barana, Fioravera, Marchisio, \& Rabellino, 2017)

Within the PP\&S Project, the activity of problem posing and solving, strongly characterized by cooperative learning, can be carried out face-to-face among students, in their classrooms or computer lab or among students at a distance, within a VLE (Virtual Learning Enviroment) dedicated to each class. At the same time, teachers develop problems for their students at a distance, within a VLE dedicated to the community of PP\&S teachers throughout Italy, who also collaborate with each other exchanging ideas, teaching strategies and materials reviewed and tested in their classes (Barana et al., 2018a). They also develop problems in collaboration with the tutors at a distance during the online training sessions (weekly tutorials and periodical training modules). To increase teachers' awareness of the use of problem posing and solving we proposed an immersive experience, in the form of a workshop, entitled "Mathematical Exploration with Problem Posing and Solving", in which we focused on the work of teachers in creating problems, in order to suggest a change of 
perspective. The 50 teachers who participated teach from primary to upper secondary school (students aged 6 to 18) and they teach Mathematics or other scientific subjects.

\section{Methodologies}

The experience was developed in three different moments:

1) Presentation of an example of a contextualized problem for the explanation of the four phases of the problem posing and solving process (problem design, text formulation, construction of the solution process, generalization of the resolution to abstract the solution process);

2) Individual step-by-step creation of a contextualized problem by the teachers following the above mentioned phases through stimulus-based questions;

3) Compilation of questionnaires. A common topic was assigned to all the teachers for the development of the problems: variation of a quantity according to another quantity, which can include mathematical concepts such as proportionality, rate of variation, incremental ratio.

Teachers were asked to think about a very specific class for which to create the problem. To analyze the considerations of the teachers on the problem posing and solving process we used the following tools: initial questionnaire, problem created by teachers, and teachers' answers to stimulus-based questions of the first two phases. For the first phase, they were: "Did you find it difficult to choose a contextualization? If yes, which ones?", "For what reasons can the contextualization chosen be effective?". For the second phase they were: "Did you encounter any difficulties in writing the text of the problem? If yes, which ones?", "What difficulties do you think students can encounter when interpreting the text of the problem?".

\section{Results}

Of the 50 teachers who participated in this experience, 7 taught at primary school, 24 at lower secondary school one of which a special needs teacher) and 19 at upper secondary school. Primary teachers taught various subjects (including Mathematics and Science), while secondary teachers taught: Chemistry (1), Physics (1), Mathematics (16), Mathematics and Physics (5), Mathematics and Science (20); except for 13 teachers, all had been teaching for more than 10 years. Most of the teachers said that they regularly used problem solving as a teaching strategy during their lessons (Figure 1), and only 3 teachers (from secondary school) never or rarely used it. 


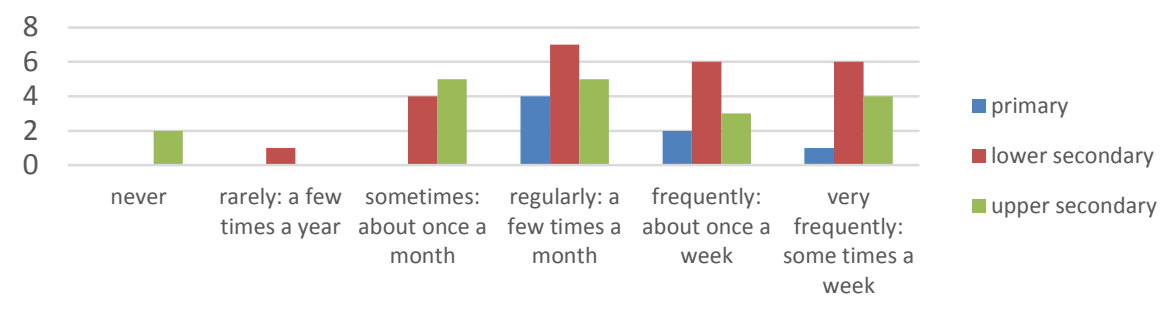

Figure 1. Frequency of use of problem solving as a teaching strategy (2018).

Some teachers preferred to work individually, while others preferred to work in pairs or groups of 3 or 4 ; the groups were spontaneously formed and in some cases teachers of different degrees or subjects worked together. At the end of the immersive experience, 25 different problems were produced. All of them are characterized by a contextualization in the real life and familiar to the students, for example charging the phone, school trips, going to the cinema, athletic preparation of a team, cooking recipes, interpreting bills. When we asked them why they chose a particular contextualization, the teachers said: "it is part of the experience of the students"; "to stimulate the observation of the places they live in", "because it allows comparisons with other disciplines". Half of the teachers had difficulties in choosing the contextualization. Some common difficulties were: connecting the theory to topics and problems that can engage students; creating texts (because they usually draw from books), little practice in designing real-world tasks and in finding real examples that can be translated in mathematical terms in a simple way. $86 \%$ of teachers said they had difficulty in drafting the text of the problem, for example in being clear and correct in the formulation of the text, in the choice of which data had to be given and which did not, or in the translation of the idea into a text. $62 \%$ of teachers decided to create a problem in which some data are open, in order to invite the student to explore the data. But, as one of the teachers stated, "leaving some data to look for makes the problem more real and stimulating, but data must be chosen wisely by the teacher". A problem with "too open" data could confuse the student who does not know how to set the solving process. An example is the following problem created by a teacher during the workshop: "Two friends who live in different places decide to meet and have to organize the trip. If they leave the same day at the same time and proceed at a constant speed, where will they meet?". Below we will show two examples of very interesting problems developed during the workshop, the first one by a primary school teacher and the second one by an upper secondary school teacher.

1) The cook of the school asks children of the fourth year to help her choose the amount of pasta to cook. There are 24 students and for each one the cook prepares $60 \mathrm{~g}$ of pasta. How many kilos of pasta does the cook need? And what if 5 children were absent? 
2) Consider your mobile phone with its specific watts (which can be found in the phone specifications). Knowing that the Italian home network supplies $230 \mathrm{~V}$, what is the charge needed to fully charge your mobile phone? And what would it be if you were in another country of your choice?

Both problems have a real context very familiar to students, in the second case some data are intentionally left open (the loading time of the phone). Moreover, both lead to a coherent generalization of the resolutive process (in the first one by varying the number of students in one class and in the second one by choosing the country). In the problem solving phase, the teachers focused on the conceptual nodes involved and on the difficulties that their students might encounter; some teachers were more concerned about the use of contextualized problems, while others were concerned about their students' skills.

\section{Conclusions}

The immersive experience led to the production of valid problems and was full of very interesting ideas. The teachers reflected upon the various phases of the problem posing and solving and on the difficulties their students might face in solving the problem, making them more aware of the activity they offered. This is why the same immersive experience can also be offered to the students. The results show that the experience can be presented at all levels and can facilitate dialogue between teachers who teach at different schools and different disciplines.

\section{References}

Barana, A., Brancaccio, A., Esposito, M., Fioravera, M., Fissore, C., Marchisio, M., Pardini, C., Rabellino, S. (2018a). Online Asynchronous Collaboration for Enhancing Teacher Professional Knowledges and Competences. In The 14th International Scientific Conference eLearning and Software for Education, 167-175, Bucharest: ADLRO. https://doi.org/10.12753/2066-026x-18-023.

Barana, A., Conte, A., Fioravera, M., Marchisio, M., \& Rabellino, S. (2018b). A Model of Formative Automatic Assessment and Interactive Feedback for STEM. In Proceedings of 2018 IEEE 42nd Annual Computer Software and Applications Conference (COMPSAC), 1016-1025. Tokyo, Japan: IEEE. https://doi.org/10.1109/COMPSAC.2018.00178.

Barana, A., Fioravera, M., \& Marchisio, M. (2017a). Developing problem solving competences through the resolution of contextualized problems with an Advanced Computing Environment. In Proceedings of the 3rd International Conference on Higher Education Advances. Universitat Politècnica València. https://doi.org/10.4995/HEAD17.2017.5505. 
Barana, A., Fioravera, M., \& Marchisio, M. (2017b). Teacher training: a model for introducing innovative digital methodologies for learning Mathematics. Proceedings of the 3rd International Conference on Higher Education Advances, 608-616. https://doi.org/10.4995/HEAD17.2017.5303

Barana, A., Fioravera, M., Marchisio, M., \& Rabellino, S. (2017). Adaptive Teaching Supported by ICTs to Reduce the School Failure in the Project "Scuola Dei Compiti". Proceedings of 2017 IEEE 41st Annual Computer Software and Applications Conference (COMPSAC), 432-437. https://doi.org/10.1109/COMPSAC.2017.44

Baroni, M., \& Bonotto, C. (2015). Problem posing e problem solving nella scuola dell'obbligo. Genova, Matematica in classe 2015. Retrieved October 23-25, 2015, from http://matematica.unibocconi.it/sites/default/files/BonottoBaroni.pdf

Brancaccio, A., Marchisio, M., Palumbo, C., Pardini, C., Patrucco, A., \& Zich, R. (2015). Problem Posing and Solving: Strategic Italian Key Action to Enhance Teaching and Learning Mathematics and Informatics in the High School. In Proceedings of 2015 IEEE 39th Annual Computer Software and Applications Conference, 845-850, Taichung, Taiwan: IEEE. https://doi.org/10.1109/COMPSAC.2015.126.

D’Amore, B., \& Fandiño Pinilla, M. I. (2006). Che problema i problemi. L'insegnamento della matematica e delle scienze integrate, 6, 645-664.

European Parliament and Council. (2018). Council Recommendation of 22 May 2018 on key competences for lifelong learning. Official Journal of the European Union, 1-13.

Kilpatrick, J. (1987). Problem formulating: Where do good problem come from? In Cognitive science and mathematics education (A. H. Schoenfeld, pp. 123-147). Hillsdale: NJ: Erlbaum.

Lavy, I., \& Shriki, A. (2007). Problem posing as a means for developing mathematical knowledge of prospective teachers. In 31st Conference of the International Group for the Psychology of Mathematics Education (Vol. 3, pp. 129-136).

Leong, Y. H., \& Janjaruporn, R. (2015). Teaching of problem solving in school mathematics classrooms. In The Proceedings of the 12th International Congress on Mathematical Education (pp. 645-648). Springer, Cham, https://doi.org/10.1007/978-3319-12688-3_79.

Liljedahl, P., Santos-Trigo, M., Malaspina, U., \& Bruder, R. (2016). Problem solving in mathematics education. New York, NY: Springer Berlin Heidelberg.

MIUR. Indicazioni Nazionali per il curricolo della scuola dell'infanzia e del primo ciclo d'istruzione (2012).

National Council of Teachers of Mathematics. Executive Summary Principles and standards for school mathematics (2000).

Pólya, G. (1945). How to solve it. Princeton NJ: Princeton University.

Samo, D. D., Darhim, D., \& Kartasasmita, B. (2017). Culture-Based Contextual Learning to Increase Problem-Solving Ability of First Year University Student. Journal on Mathematics Education, 9(1). https://doi.org/10.22342/jme.9.1.4125.81-94

Singer, F. M., Ellerton, N. F., \& Cai, J. (2015). Mathematical problem posing: from research to effective practice. New York: Springer. 
Stoyanova, E., \& Ellerton, N. F. (1996). A framework for research into students’ problem posing in school mathematics. In Technology in mathematics education (P. C. Clarkson (Ed.), pp. 518-525). Melbourne, Australia: Mathematics Education Research Group of Australasia.

Unione Matematica Italiana. Matematica 2001 (2001). 